\title{
The coexistence claim and its possible implications for success in teaching for conceptual "change"
}

\author{
Patrice Potvin ${ }^{1}$ \\ ${ }^{1}$ Département de didactique, Université du Québec à Montréal, Montréal, Canada \\ For correspondence: potvin.patrice@uqam.ca
}

\begin{abstract}
This article presents recent research results in mental chronometry and neuroimaging that support the coexistence of multiple conceptions. It then presents and elaborates on six possible implications for an adherence to the coexistence claim within the context of scientific conceptual learning: (1) stop the war on misconceptions; (2) use a different chronology for students with lower background knowledge; (3) give cognitive conflict a new function; (4) avoid personal prejudice; (5) reaffirm the importance of the durability of "change"; and (6) teach science as early on as possible. A discussion of these implications and a biology-based analogy about conceptual understanding is also proposed.
\end{abstract}

Keywords: science teaching, conceptual change, coexistence, prevalence, persistence.

\section{Conceptual change: altering initial conceptions}

In the classical approach to "conceptual change" (Duit \& Treagust, 2012), students' conceptions that do not align with the scientific conceptions to be taught are generally considered as needing, not surprisingly, to be "changed." This idea of "change" in the expression "conceptual change" implicitly suggests that some kind of operation has to be performed on initial and "deviant" knowledge in order to eventually alter it. Thus it follows that to be successful, teachers must first record the presence of these conceptions and, if they have the time and resources, to ascertain their nature in order to prepare and apply the most appropriate pedagogical treatments.

In the classical approach, it is considered crucial that targeted "misconceptions" have to be weakened, fragilized or somehow discredited by revealing their shortcomings. This is often done by showing that they cannot be successfully applied to the resolution of all problems, especially less familiar ones, or by revealing contradictions that can exist between the beliefs of different individuals. The aim behind such "preventive strikes" is to lower the credibility status of the identified conceptions and make learners more receptive to teachers' propositions, by triggering motivation (to replace them) or by activating cognitive mechanisms that might definitively resolve any logical conflicts that arise. The purpose of conceptual-or cognitive-conflict is therefore to secure an alteration of initial and undesirable conceptions. Whether it is accepted that misconceptions must be "forgotten" or "transformed," we believe it is central to the conceptual change paradigm that such unexpected conceptions must not be left intact.

There appears to be a consensus that conceptual change is concerned with restructuring of existing knowledge [...] a non-scientific conception held by a student would be replaced or extinguished [...]. (Tyson, Venville, Harrison, \& Treagust, 1997, p. 391) 
[...] They have to be, according to the concept of change, either completely abandoned (Villani, 1992), modified (Limon, 2001), "replaced" (Posner, Strike, Hewson, \& Gertzog, 1982, p. 212), "reorganized" (Jensen \& Finley, 1995, p. 149), eliminated (Nersessian, 1998), rejected (Hewson, 1981, p. 385), transformed or "restructure[d]" (Limon, 2001, p. 359). (Potvin, 2013)

As decades passed, we saw fewer and fewer conceptual change articles that presented "change" as a "replacement," and more and more articles that presented it as a "reconfiguration" of initial knowledge. Until recently, it was even suggested that

it may be timely to replace the term [conceptual change]. We agree [...] that this term "conceptual reconstruction" more appropriately indicates the actual meaning predominating $[\ldots]$ and we recommend the use of the latter term be considered in the future to indicate conceptual learning [...] (Duit \& Treagust, 2012, p. 50)

This idea of "reconstruction" implicitly suggests that misconceptions are made up of smaller elements, and that these elements are sensitive to the particular conceptual ecologies in which they exist. Indeed, the idea of "reconstructing" implies that sub-elements or the relationships that coordinate them should be preserved in the process of learning, whereas others should be rejected or new ones inserted into the "conceptual ecology." Consistent with this idea of "reconstruction," much research conducted during the "90s and early 2000s concentrated on the cognitive resources that constrain such "reconstructions" when initial conceptions interfere. Such resources were sometimes called p-prims (DiSessa, 1993), intuitive rules (Stavy \& Tirosh, 2000), core intuitions (Brown, 1993), ontological frameworks (Vosniadou, 1994), heuristics (Gigerenzer \& Todd, 1999; Maeyer \& Talanquer, 2013), etc. These perspectives were therefore attentive to the nature of the elements that were coordinated, to the articulation habits that link them together, or to the conformity of the construction to other patterns of beliefs. In this framework, conceptual changes were sometimes presented as "allosteric" (Giordan \& Girault, 1992). This term, borrowed from biology, refers to the behaviour of a molecule that changes configuration when binding with new molecules, such as when hemoglobin changes shape (and temporarily its composition) when accepting oxygen. In this analogy, misconceptions could modify their shape (accommodation) and their composition when new crucial information has to be assimilated.

We believe these research efforts are genuinely scientific, because they strove to identify invariants in students' reasoning, verbalizations or performances. We could argue that they tackled the immense problem of the "genotype" of conceptions, refusing to consider the mere verbalizations produced by students as worthy objects of treatment, but rather concentrating on the redundant structural similarities that appear among them. In this scientific context, verbalizations are considered as showing high variability and apparent volatility, and are therefore somehow (and implicitly) considered as the mere "phenotype" of comprehension, and thus not as interesting as the rules that generate it, and the elements that compose it.

However, these considerable efforts were mostly descriptive and did not lead to many outstanding generalizable teaching prescriptions. In our opinion, they nevertheless were and remain highly important and valuable for teachers because they provide original analytical frameworks for interpreting students' reactions, and perhaps, above all, they provide a smaller number of objects to monitor than the multitude of possible conceptions. 


\section{Accumulating evidence for the coexistence of conceptions}

However, in recent years, research efforts have accumulated evidence that abandoning or altering initial conceptions might not necessarily happen during conceptual learning. Such results have been obtained, among others, by means of mental chronometry and neuroimaging.

For example, Shtulman (2012), Babai (Babai \& Amsterdamer, 2008; Babai, Sekal, \& Stavy, 2010) and (Potvin et al., 2015) have shown that correct answers given to scientific problems take longer to be produced if these problems involve a possible misconception than if they do not (all other things being equal). Such results constrain the conclusion that even though correct answers may be given, there is still something that interferes with their production. For these authors, the only possible explanation is that the recorded interference is caused by sly misconceptions that have survived learning, persisted and thus have not been abandoned or transformed during the learning process.

Neuroimaging studies have also reached this conclusion by recording cerebral activations that are typical of the cognitive function of inhibition when expert answers are given for counterintuitive scientific problems (stimuli) in comparison to similar but intuitive problems (stimuli) in science. Such activations have been recorded for scientific (Brault Foisy et al., 2015; Masson et al., 2014; Potvin et al., 2014) and geometry (Stavy \& Babai, 2010) problems. It has been interpreted that since the cognitive function of inhibition is triggered during the successful resolution of scientific problems that involve a conceptual distractor, then the only possible target of this inhibition work must be misconceptions that persist in participating in resolution efforts, while not necessarily prevailing. The conclusion is the same for mental chronometry studies: the development of expertise does not require the elimination or restructuration of previous knowledge, but it does require its inhibition, consciously or not.

In addition, scientific experts who have impaired cognitive functions (Lombrozo, Kelemen, \& Zaitchick, 2007) or adults put under speeded pressure (Kelemen \& Rosset, 2009) have shown more adherence to explanations that are usually associated with naive (teleological) conceptions of the world, and that are usually preferred by children. This suggests that such conceptions have persisted despite adulthood or scientific expertise.

This idea of the "coexistence" of multiple conceptions is, however, not entirely new in science education. Implicit suggestions of similar ideas can be found in articles from the '80s and '90s (Hewson, 1981; Solomon, 1983). Other authors have even formulated the idea quite explicitly (Chi, 1991; Galili \& Bar, 1992; Linder, 1993; Mortimer, 1995; Tyson et al., 1997). Some synthetic observations of this kind were also made by Reinders Duit at a symposium on conceptual change (cited by Tyson): "There is not a single study listed in the leading bibliographies of research on students' conceptions [...] in which a student's conception [...] could be totally extinguished and replaced by a new idea [...] old ideas basically stay 'alive' in particular contexts" (Tyson et al., 1997, p. 392). This surprising conclusion appears to us as being in direct contradiction to the "restructuration of conceptions" claim, because if conceptions are indeed reconstructed, then how can their initial form continue to interfere? Therefore, we do not believe that it is logically possible to accept both the reconstruction and coexistence claims.

We believe that the idea of coexistence was never really accepted within the conceptual change field, possibly due to a lack of convincing evidence, and due to the important domination of the "replacement" and "transformation" (Ohlsson, 2009) paradigms, which, somehow, might have blinded us for many years and forced us to consider unduly the survival and apparent resurrection of initial ideas as merely being tolerable anomalies. 
It is also possible that the existence of unconscious yet interfering conceptions can be hard to believe. Indeed, humans are used to being conscious of only one perceived-as-dominant idea at a time, and instances when a conflict between ideas becomes conscious are not frequent; therefore, seeing ideas as the result of some sort of silent debate or invisible conflict within the mind might be a difficult thing to do.

However, we believe recent evidence has sparked a debate and requires that we go further in anticipating what the consequences of a complete and radical acceptance of the coexistence claim could be, and to propose a series of tangible and manageable implications for science teaching, but also for in-class research initiatives.

\section{Possible implications of coexistence for science teaching}

In the following sections, we will propose an analysis of the possible consequences and implications for science teaching that would result from the acceptance of the coexistence claim. We have chosen to concentrate on the most concrete implications that might have the clearest repercussions in a science class, instead of the more theoretical implications that might interest, for example, psychology theory.

\section{Implication No. 1: Stop the war on misconceptions}

Of course, we are not suggesting that misconceptions should be ignored by educators, or that educators should not care about their possibly disruptive nature. However, since recent research has suggested that even scientific experts have to inhibit misconceptions in order to perform (and that they are also prone during certain, perhaps stressful, situations to let more naive explanations prevail), it might seem pointless to try to discredit them for what they are and to systematically plan for their elimination or restructuration by making them targets. Apparently, expertise does not necessitate such an elimination or transformation. It does not even appear to be possible, since differences in response times and inhibition mechanisms between congruent and incongruent stimuli can be recorded even with the greatest available experts. It also remains possible that expertise, often associated with flexibility and adaptation, in fact requires that alternative explanations be available for an appropriate evaluation of problems, but also that they be inhibited if judged necessary according to the context. Research on expertise has indeed shown that one of the most important differences that exists between experts and novices is the selection of information that is relevant and also the quick rejection of information that is not (Gigerenzer, 2007).

If the abandonment or reconfiguration of misconceptions appears to be vain, would it be productive to strive to at least lower their credibility status? Research seems to indicate that lowering credibility statuses is unlikely. Consider this simple experiment, described by Robert Burton, who provides a very interesting example of the irreversibility of what he calls "the feeling of knowing." Read and consider the following paragraph, and then immediately consider the degree of confusion it could induce in readers (and in you, the reader):

A newspaper is better than a magazine. A seashore is a better place than the street. At first it is better to run than to walk. You may have to try several times. It takes some skill but it is easy to learn. Even young children can enjoy it. Once successful, complications are minimal. Birds seldom get too close. Rain, however, soaks very fast. Too many people doing the same thing can also cause problems. One needs lots of room. If there are no complications, it can be very peaceful. A rock will serve as an anchor. If things break loose from it, however, you will not get a second chance. (Burton, 2008, p. 5) 
At first, reading this paragraph can be very confusing and it might appear meaningless and without any common thread. But the use of a single concept, "kite," will change all of that. Knowing that the paragraph is about this unifying "kite" concept will completely change your perspective and probably fill you with some sort of conceptual comfort. But what is most interesting is that, when we read the text a second time while thinking of a kite, it becomes virtually impossible to retrieve or reproduce the initial state of confusion we were in during the first reading. It is also quite difficult to imagine what it would be about if someone told us that, ultimately, the paragraph is not about a kite, but about something else, something very different. And indeed, systematically studying some of the paragraph's weaknesses in describing kites might not necessarily lead to a reduction in the credibility status of the concept of kite as a valid one in this case. Sorry, the kite will remain in your mind forever.

In the same manner, we believe that the credibility status of a conception cannot easily be lowered, even if we provide many good arguments. However, the classical models of conceptual change have clearly counted on this possibility:

[...] Early work on conceptual change assumed that prior conceptions held by the learner would be eliminated perhaps through a process of creating a dissatisfaction [...] The status of the existing conception would [then] be lowered. (Tyson et al., 1997, p. 393)

The frequent conceptions we cultivate about the natural world we live in have probably been proven fertile and productive on many occasions in the past, and therefore we might actively resist attempts to disqualify them as valid. Indeed, many instances of rejections of contradictory evidence, modifications of application fields, or even transformations of recorded memory (some kind of memory falsification) might be conducted by learners in order for them to preserve their cherished core beliefs, as many researches in psychology have revealed through their study of confirmation biases (Koslowski \& Maqueda, 1993). Fugelsang and Dunbar have also shown that the mind seems to get actively disinterested in data that conflict with the ideas that are judged to be plausible (Fugelsang \& Dunbar, 2005). These authors have suggested, based on neuroimaging, that discordant information is often treated as errors and not as productive anomalies that should trigger closer examination.

It is not impossible that "forgetting" (a conception, or a part of it) can be an active and even an essential and productive function of the mind (some sort of "cleaning up" function), but it is difficult to imagine how one teacher could actively favour it from the outside.

On the contrary, it is possible that attempts to evoke misconceptions, even if this is done with the intention of discrediting them, could in certain cases be detrimental, through suggestion effects (Potvin et al., 2012). Indeed, Gigerenzer has proven that when we recognize something more easily, it might gain credibility [see recognition heuristic, (Gigerenzer \& Todd, 1999)], like when an advertisement repetitively shows a logo (without even bothering to show the products to be sold). Therefore, it is not impossible that talking about a misconception without taking all possible and necessary precautions (which might be difficult) could favour its subsequent recognition, and therefore have the undesired effect of increasing its credibility status. Kloos has also suggested that "giving priority to the mistaken performance might, in fact, be counterproductive if it increases the salience and possible coherence of constraints that support making an error" (Kloos, Fisher, \& Van Orden, 2010, p. 626). From her 2010 study, she concluded that "results from our study suggest that such a procedure, rather than calling to mind existing beliefs, might in fact create and perpetuate them." 
Implication No. 2: In certain cases, use a different chronology

However, we believe it still might appear inappropriate to completely avoid conflictual events between the knowledge to be learned and initial misconceptions. After all, conceptual change models, which most of the time contain a "cognitive conflict" phase, have been proven to be more effective than approaches that are essentially "transmissive" (Duit, Treagust, \& Widodo, 2008; Vosniadou, 2008). Still they do not provide total satisfaction and have been heavily criticized because of this (Eylon \& Linn, 1988; Guzetti, 1993; Limon \& Carretero, 1997). They have been judged as producing changes that are too superficial and have the largest effect only on students with the strongest initial background.

One of the reasons for such shortcomings may lie in the particular way that conflicts are triggered. First, they are presumed to be provoked by introducing credible anomalous data or discrepant events (Nussbaum \& Novick, 1982). Discrepant events are presented as special cases in which the presumed misconceptions will lead to erroneous predictions or interpretations. It is believed that an accumulation of such anomalies will naturally lead to a rejection or a change in paradigm, like what usually happens in the history of science (Kuhn, 1962). But what happens in the scientific community does not seem to be as easily transferable to individuals: "there is at this time no extensive body of empirical proof that the pedagogical technique of creating dissatisfaction by confronting students' prior conceptions with anomalies is effective in improving understanding of counterintuitive scientific subject matter" (Ohlsson, 2009, p. 21).

Ohlsson also invokes what he calls the "assimilation paradox" (2009, p. 22), and argues that if learners come to be exposed to new and crucial information, they have no choice but to interpret it with the sole available conceptual framework that they have. Thus they might understand this data (or parts of it) in a way that will, in turn, reinforce their available model instead of discrediting it. "We see only what we know beforehand," says Goethe.

In his proposition, Ohlsson also suggests that "theory-data conflicts are unpromising as engines of conceptual change, given that people are not particularly adept at handling that relationship" (p. 32), and that it might be preferable to create "theory-theory conflicts" (ibid.) instead. Our interpretation of this proposition leads to the suggestion that for students who do not initially dispose of a rival theory to contrast with the presented scientific models, conflict (and therefore learning) cannot occur. This might explain why students with the weakest initial conceptual backgrounds do not benefit as much from teaching sequences that are based on classical models. Thus for these students, it might be more beneficial to begin teaching sequences by presenting the desired scientific model instead of directly beginning by showing anomalies (Potvin et al., 2015). This could secure the availability of the desired conception that consequently will allow productive-and possibly more easily explicitable-internal or social "theory-theory" conflicts.

\section{Implication No. 3: Give cognitive conflict a new function}

Such a theory-theory competition for cognitive utility can hardly be resolved by merely examining the plausibility or intrinsic merits of both theories. To a degree, they have to be tested to see if they conform to reality. Of course, during scientific training, we expect students to be rational and act like scientists. Instead, Ohlsson suggests that conflicts of this kind can be resolved on the basis of the respective cognitive utilities (2009, p. 23) of competing models. Nevertheless, whether it is for authentically scientific reasons or for cognitive utility, it remains that such competitions do not seem to have the power to lower credibility statuses. However, we believe they have the potential to stop or hold back increases in credibility statuses.

By associating different conceptions with different contexts, we believe that teachers and students can pinpoint cases where this match produces shortcomings in performance (instances in which 
conceptions don't work). However, since lowering the status of conceptions appears to be difficult, we propose shifting the teaching focus onto the contexts rather than onto the conceptions themselves. If students positively develop alertness for certain "delicate" contexts in which certain conceptions cause failure, then we believe that they can develop inhibitive reflexes, not for the conceptions themselves, but for certain conception-context associations. If they are able to restrain from using certain conceptions in certain contexts, we believe it can provide favourable and possibly durable circumstances in which the presented scientific conceptions can eventually gain status, maybe enough to prevail-and possibly durably prevail-in the competition for cognitive utility. Of course, invitations for the inhibition of defective conception-context cases have to be frequent enough to eventually be automated and then create sustained circumstances that can favour prevalence shifts.

This idea of de-centration from the conceptions and re-centration on the contexts has already been proposed (although in a slightly different context). In 1993, Linder (p. 78), cited by Mortimer (1995, p. 268), wrote: "science educators' depiction of learning should be extended so that less emphasis is put on students' existing repertories of conceptualisations and more effort on enhancing students' capabilities to distinguish between conceptualisations in a manner appropriate to some specific contexts."

At the end, we believe that since "reductions of statuses" initiatives appear futile, teachers might benefit from seeing science teaching as essentially being an additive process, in which they can only positively bring and the secure new comprehension elements: new ideas, but also new vigilances.

\section{Implication No. 4: Avoid personal prejudice}

We believe that taking the previously described precautions (implications 1,2 and 3) in the context of science education could help avoid certain negative affective effects on certain students. Indeed, it is possible that even the slightest blunders in conceptual "attacks" could be interpreted by learners as acts of aggression against their intellectual capacities. Such perceptions could have a very negative effect on their self-concept (Martinot, 2001) and interest.

Concentrating students' attention on conceptual objects and on the relationships that link them together instead of focusing on the relative value and merits of different possible conceptions or misconceptions has the potential to preserve their self-esteem and their interest in science. It is the same for cultivating messages according to which all ideas, regardless of their author, might have plausibility, contextual or local fertility, and can reveal intelligence, but might also ultimately be unequal in the face of certain pieces of evidence or confirmed (or infirmed) hypotheses. Indeed, authors have long demonstrated the positive impact of self-efficacy and interest on science achievement (Juriševič, Vrtačnik, Kwiatkowski, \& Gros, 2012), but also specifically on "maintaining conceptual change learning over time for learners with high confidence in prior knowledge" (Cordova, Sinatra, Jones, Taasoobshirazi, \& Lombardi, 2014, p. 173).

All educators know the potentially devastating effect of punitive teaching. We believe that rigorously operating within a coexistence framework can contribute to avoiding this kind of damage, because the negative reinforcement becomes directed toward a local or circumstantial inapplicability of certain ideas instead of toward the ideas themselves. Indeed, students sometimes initially have trouble distinguishing themselves from their ideas. Thus attacks on conceptions can unfortunately too often be perceived as attacks on individuals.

But all this supposes more than small adjustments in practice or punctual change of tones. We believe it supposes fundamental and probably difficult changes in pedagogical culture. 
Implication No. 5: Reaffirm the importance of the durability of "change"

It is not uncommon to see teachers quickly get frustrated when their students appear to fail miserably at solving problems that they could successfully solve the day before. We also see this phenomenon with parents doing homework with their children. Such parents can sometimes get very angry when they see their child backslide despite all the work, commitment and dedication they recently applied to doing their homework.

We believe that such situations are the result of an implicit compliance with the "transformation paradigm." If educators believe that knowledge undergoes a transformation when learning occurs, then it seems perfectly normal that old conceptions should not manifest in their initial form anymore after such a transformation. Such a reversal to initial beliefs would indeed appear unlikely because it would require a costly reconstruction of the initial conception. However, as implausible as they may seem, reversions to initial conceptions (that cannot be easily explained only by forgetfulness) do seem to occur. And they do so quite often.

We believe that old misconceptions often resuscitate after successful learning because of coexistence. Old conceptions are neither forgotten, nor transformed. They may not even be dormant. But it is possible that teaching efforts have added new ones, which were able to prevail for a short time. This interpretation suggests that there are recency effects, similar to the ones described by Baddeley and Hitch (1993), and that these effects tend to temporarily increase the status of a recently taught conception, making it, at least in a phenotypical way, appear as if it were the sole and final product of a conceptual change. But the genotype of conceptions might not have been altered, nor has the recently taught conception been forgotten. An indication of its persistence, although without immediate manifestation, would be that if a learner studies it again, it would take a shorter time to come back as strongly as it did the first time.

If we fully accept the idea of coexistence, we must interpret relapses as a shifting back in prevalence, and we must also accept that the race between conceptions can never be definitely won. Therefore, obtaining a durable prevalence of scientific conceptions appears as a much harder task than merely obtaining phenotypical conceptual changes (a change in answers). It nevertheless appears to us that, most of the time, schools are satisfied with the latter. When we examine the structure of textbooks or semester-scale teaching planning, we see that exercises and tests seem to capitalize on the recency effect, instead of testing for durable, genotypical changes. Typically, tests are never given long after lessons.

We believe that research that has been conducted on the virtues of repetition and "spacing effects" could inform conceptual change possibly as much as it has for memory. Many very promising results on such effects have been obtained as meta-analyses have recorded educationally important magnitude effects $[d=0.46$ (Donovan \& Radosevitch, 1999); $d=0.71$ (Hattie, 2009)]. They have also been conjectured to work for complex tasks (possibly like the ones that lead to conceptual "changes") as well as for simpler ones (Carpenter, Cepeda, Rohrer, Kang, \& Pashler, 2012; Kornmeier, Spitzer, \& Sosic-Vasic, 2014), and have also been tested with success in the acquisition of science concepts (Vlach \& Sandhofer, 2012). All of these research efforts have shown the importance of the number of repetitions (although after a certain number, performance hits a ceiling) and of spaced distribution of these repetitions in time (instead of clustered), but also that expanding spacing is better than regular spacing (Kang, Lindsey, \& Mozer, 2014).

We believe that research designs that are similar to those used in this promising research field should be imported and tested in our so-called "conceptual change" field in order to contribute to a likely improvement in the durability of conceptual prevalence or "change". 
Indeed, we believe that a short and fragile period of time exists in a teaching sequence (or longer) when students are able to put two competing conceptions, the initial one and the desired one, into a possibly fertile conflict. We believe that such a window is a precious and ephemeral instant. In most of the teaching efforts that we observe, this window unfortunately marks the end of the teaching project. However, we believe that it is merely the first yet indispensable step toward quality and durable learning. It is the "sacred" moment when cognitive conflict has the potential to work and therefore it must not be neglected. If it is, much work will most likely have to be done just to reach that point again. If we understand and consider the importance of that particular learning instant, then we believe that an automatization program must immediately and systematically be started, without ever assuming that the menace of the initial conception will be dissolved.

\section{Implication No. 6: Appropriately teach science as early on as possible}

Considering the amount of research that concludes that conceptual learning is hard to secure, and considering the complexity of the factors, pitfalls and mechanisms described above, it is clear that it would be preferable to avoid having to go through all of this trouble. Indeed, instead of investing so much energy into fixing conceptions, maybe we could spend more energy on avoiding the prevalence of defective conceptions from the beginning. We thus believe that correctly and intensively teaching science as early as possible in life could significantly improve science education later in life. But a certain degree of vigilance must also be exercised with regard to the quality of teaching at all levels. For example, Cormier (2014) recently showed that certain misconceptions in chemistry at the college level can be attributed to imprecise or erroneous exposure to such concepts in school. Many other examples exist in the elementary-secondary transition. Deficiencies in the quality-and putting off until later-of science education have therefore much larger-and longer-term-effects than the immediately visible ones. We therefore suggest a reinforcement of the quality of science education and recommend reinforcing it at the earliest levels in the hope that some obstacles will be neutralized when the complexity increases. The benefits could be doubled. Currently, a quick analysis of the literature on elementary teacher competence in science does not indicate a satisfactory level.

\section{Conclusion}

We believe that the new and recent set of neuroeducational evidence forces us to see beyond the ideas of replacement or transformation of knowledge. In 2012, Duit and Treagust suggested that it may be time to replace the term "conceptual change" with "conceptual reconstruction" (Duit \& Treagust, 2012, p. 50). In line with recent developments, we respectfully disagree and, instead, suggest that the idea of "conceptual prevalence" might be a better fit, and also that new terminology might henceforth constrain the field in a more productive way. Among such terminology, the ideas of "persistence" (Babai et al., 2010; Shtulman \& Valcarcel, 2012; Solomon, 1983), "coexistence" (Mortimer, 1995), and "prevalence" (Potvin, 2013; Potvin et al., 2015) could be considered and adopted by the community or researchers.

We also suggest that we can draw an interesting analogy between scientific comprehension and concepts borrowed from the field of biology. The concepts of phenotype and genotype could be used to support an understanding of the differences that exist between apparent changes in conceptions (verbalizations, performances, answers) and more profound ones (representations, conceptions, the use of p-prims, intuitive rules, etc.). First, this distinction could be useful to understanding that a change in phenotype does not necessarily mean that a substantial change in genotype has occurred. The transformation of an aquatic tadpole into a terrestrial frog does not result in a change in species. Similarly, if we confuse conceptions with their expression, then "conceptual changes" can be concluded every time verbalizations change, which is not necessarily the case. Thus, it is important to see that a change in answers does not mean that a conceptual change has occurred. 
But our proposition goes further. Within such a framework, we suggest that the coexistence claim allows us to see that the genotype might not be as "transformable" as was previously thought, and that it might be preferable to see some conceptual changes not as genetic, but rather as epigenetic phenomena. In this additional analogy, apparent performances (phenotype) depend not only on the availability of plausible conceptions (genotype), but also (and above all) on their possible expression (or their non-expression), just like visible characteristics of living organisms depend not only on their genetic baggage, but also on the fact that the environment in which they live can favour the expression (or not) of certain elements of this genetic material (rabbits change colour in winter; ants and bees become queens or workers, depending on what is fed to them, etc.). Just like some DNA sequences can prevail in certain circumstances, we believe that certain conceptions can prevail in certain contexts.

In previous publications, we have made a concrete proposition for a conceptual prevalence teaching model (Potvin, 2013) and have tested it with some success by reducing it to sequencing considerations in comparison with a more "classical" reduction in conceptual change models (Potvin et al., 2015). We refer the reader to these publications for a more complete description of the model, but we can summarize its main steps: 1 ) secure the availability of the programmed (desired) conception; 2) install inhibitive "stop signs"; and 3) work for durable prevalence of the programmed conception (Potvin, 2013, pp. 29-32). Within this scenario, it is suggested that initially prevailing misconceptions can, with adequate teaching, be "overtaken" by new knowledge, in some sort of never-ending race between competing conceptions (Potvin et al., 2015, p. 1088).

This proposition, however, still has to be more thoroughly tested and contrasted with other alternative or "cousin" propositions. It is also incomplete in and of itself. Indeed, if it argues for providing initial availability of the desired conception, it does not provide, for the moment, any means to secure it. It might therefore be important to draw on other research efforts that provide a means to favour intelligibility of the desired conceptions. Also, if the model insists on the importance of favouring durable prevalence of the desired conception through automatization, it does not give any indication as to how this automatization can be achieved, except trivially suggesting repetition and variety in order to increase plausibility and fruitfulness. We believe, as was previously suggested, that studies on the spacing effect, for example, could provide precious clues. We can also conjecture that an automatization of the inhibitive "stop signs" could be as important as an automatization of the use of the desired conceptions, and therefore that teachers should always keep their eye on possible competing misconceptions, even after improvement in performance.

We have tried to conjecture what could be six of the most interesting consequences of an adherence to the coexistence claim for the purposes of succeeding in conceptual learning when conceptual obstacles are present. We hope that these suggestions more thoroughly tested by educators and researchers and eventually adopted if proven fertile. We are open to any feedback that the community might provide.

\section{Acknowledgements}

We would like to thank Guillaume Malenfant-Robichaud for his comments and encouragements as well as the members of the Science and technology education research team (ÉREST) for the discussions that lead to this article. 


\section{References}

Babai, R., \& Amsterdamer, A. (2008). The persistence of solid and liquid naive conceptions: A reaction time study. Journal of Science Education and Technology, 17, 553-559.

Babai, R., Sekal, R., \& Stavy, R. (2010). Persistence of the intuitive conception of living things in adolescence. Journal of Science Education and Technology, 19, 20-26.

Baddeley, A. D., \& Hitch, G. (1993). The recency effect: Implicit learning with explicit retrieval? Memory and Cognition, 21(2), 145-155. doi: 10.3758/BF03202726

Brault Foisy, L.-M., Potvin, P., Riopel, M., \& Masson, S. (2015). Is inhibition involved in overcoming a common physics misconception in mechanics? Trends in Neuroscience and Education, Online First. doi:10.1016/j.tine.2015.03.001

Brown, D. E. (1993). Refocusing core intuitions: A concretizing role for analogy in conceptual change. Journal of Research in Science Teaching, 30, 1273-1290.

Burton, R. A. (2008). On being certain: Believing you are right even when you're not. New York, NY: St. Martin's Press.

Carpenter, S. K., Cepeda, N. J., Rohrer, D., Kang, S. H. K., \& Pashler, H. (2012). Using spacing to enhance diverse forms of learning: Review of recent research and implications for instruction. Educational Psychology Review, 24(3), 369-378. doi: 10.1007/s10648-012-9205-z

Chi, M. T. H. (1992). Conceptual change within and across ontological categories: Examples from learning and discovery in science. In R. Giere, \& H. Feigl (Eds.), Cognitive models of science: Minnesota studies in the philosophy of science (pp. 129186). Minnesota: University of Minnesota Press.

Cordova, J. R., Sinatra, G. M., Jones, S. H., Taasoobshirazi, G., \& Lombardi, D. (2014). Confidence in prior knowledge, selfefficacy, interest and prior knowledge: Influences on conceptual change. Contemporary Educational Psychology, 39, 164174. doi: 10.1016/j.cedpsych.2014.03.0060361-476X/

Cormier, C. (2014). Étude des conceptions alternatives et des processus de raisonnement des étudiants de chimie du niveau collégial sur la molécule, la polarité et les phénomènes macroscopiques. (Doctoral dissertation). Université de Montréal.

DiSessa, A. A. (1993). Toward an epistemology of physics. Cognition and Instruction, 10(2), 105-225.

Donovan, J. J., \& Radosevich, D. J. (1999). A meta-analytic review of the distribution of practice effect: Now you see it, now you don't. Journal of Applied Psychology, 84(5), 795-805. doi: 10.1037/0021-9010.84.5.795

Duit, R. H., \& Treagust, D. F. (2012). Conceptual change: Still a powerful framework for improving the practice of science instruction. In K. C. D. Tan, \& K. Mijung (Eds.), Issues and challenges in science education research (pp. 43-54). Netherlands: Springer.

Duit, R. H., Treagust, D. F., \& Widodo, A. (2008). Teaching science for conceptual change: Theory and practice. In S. Vosniadou (Ed.), International handbook of research on conceptual change (pp. 629-646). New York, USA: Routledge.

Eylon, B., \& Linn, M. C. (1988). Learning and instruction: An examination of four research perspectives in science education. Review of Educational Research, 58(3), 251-301.

Fugelsang, J. A., \& Dunbar, K. N. (2005). Brain-based mechanism underlying complex causal thinking. Neuropsychologia, 43(8), 1204-1213.

Galili, I., \& Bar, V. (1992). Motion implies force: Where to expect vestiges of the misconception? International Journal of Science Education, 14(1), 63-81.

Gigerenzer, G. (2007). Gut feelings: The intelligence of the unconscious. London, England: Penguin Books.

Gigerenzer, G., \& Todd, P. M. (1999). Simple heuristics that make us smart. New York, NY: Oxford University Press.

Giordan, A., \& Girault, Y. (1992). Un environnement pédagogique pour apprendre : Le modèle allostérique. Repères : Essais en éducation (14), 95-124.

Guzetti, B. J. (1993). Promoting conceptual change in science: A comparative meta-analysis of instructional interventions from reading education and science education. Reading Research Quarterly, 28(2), 116-159.

Hattie, J. (2009). Visible learning: A synthesis of over 800 meta-analyses relating to achievement. New York, NY: Routledge.

Hewson, P. W. (1981). A conceptual change approach to learning science. European Journal of Science Education, 3(4), 383-396.

Jensen, M. S., \& Finley, F. N. (1995). Teaching evolution using historical arguments in a conceptual change strategy. Science Education, 79(2), 147-166.

Juriševič, M., Vrtačnik, M., Kwiatkowski, M., \& Gros, N. (2012). The interplay of students' motivational orientations, their chemistry achievements and their perception of learning within the hands-on approach to visible spectrometry. Chemistry Education Research and Practice, 13, 237-247. doi: 10.1039/c2rp20004j

Kang, S. H. K., Lindsey, R. V., Mozer, M. C., \& Pashler, H. (2014). Retrieval practice over the long term: Should spacing be expanding or equal-interval? Psychonomic Bulletin and Review, 21, 1544-1550. doi: 10.3758/s13423-014-0636-z

Kelemen, D., \& Rosset, E. (2009). The human function compunction: Teleological explanation in adults. Cognition, 111(1), 138143.

Kloos, H., Fisher, A., \& Van Orden, G. C. (2010). Situated naïve physics: Task constraints decide what children know about density. Journal of Experimental Psychology, 139(4), 625-637. doi: 10.1037/a0020977

Kornmeier, J., Spitzer, M., \& Sosic-Vasic, Z. (2014). Very similar spacing-effect patterns in very different learning/practice domains. PLoS ONE, 9(3), Online. doi: 10.1371/journal.pone.0090656

Koslowski, B., \& Maqueda, M. (1993). What is confirmation bias and when do people actually have it? Merrill-Palmer Quarterly, 39(1), 104-130.

Kuhn, T. S. (1962). La structure des révolutions scientifiques. Paris: Champs-Flammarion. 
Limon, M. (2001). On the cognitive conflict as an instructional strategy for conceptual change: A critical appraisal. Learning and Instruction, 11, 357-380.

Limon, M., \& Carretero, M. (1997). Conceptual change and anomalous data: A case study in the domain of natural sciences. European Journal of Psychology of Education, 12(2), 213-230.

Linder, C. J. (1993). A challenge to conceptual change. Science Education, 77(3), 293-300.

Lombrozo, T., Kelemen, D., \& Zaitchick, D. (2007). Inferring design: Evidence of a preference for teleological explanations in patients with Alzheimer's disease. Psychological Science, 18(11), 999-1006.

Maeyer, J., \& Talanquer, V. (2013). Making predictions about chemical reactivity: Assumptions and heuristics. Journal of Research in Science Teaching, 50(6), 748-767. doi: 10.1002/tea.21092

Martinot, D. (2001). Connaissance de soi et estime de soi : Ingrédients pour la réussite scolaire. Revue des sciences de l'éducation, 27(3), 483-502. doi: 10.7202/009961ar

Masson, S., Potvin, P., Riopel, M., \& Brault Foisy, L.-M. (2014). Differences in Brain Activation Between Novices and Experts in Science During a Task Involving a Common Misconception in Electricity. Mind, Brain, and Education, 8(1), 44-55.

Mortimer, E. F. (1995). Conceptual change or conceptual profile change? Science and Education, 3, 267-285.

Nersessian, N. J. (1999). Model-based reasoning in conceptual change. In L. Magnini, N. J. Nersessian, \& P. Thagard (Eds.), Model-based reasoning in scientific discovery. New York, NY: Kluwer Academic.

Nussbaum, J., \& Novick, S. (1982). Alternative frameworks, conceptual conflict and accommodation: Toward a principled teaching strategy. Instructional Science, 11, 183-200.

Ohlsson, S. (2009). Resubsumption: A possible mechanism for conceptual change and belief revision. Educational Psychologist, $44(1), 20-40$.

Posner, G., Strike, K., Hewson, P., \& Gertzog, W. (1982). Accommodation of a scientific conception: Toward a theory of conceptual change. Science Education, 66(2), 211-227.

Potvin, P., Masson, S., Lafortune, S., \& Cyr, G. (2015). Persistence of the intuitive conception that heavier objects sink more: A reaction time study with different levels of interference. International journal of science and mathematics education, 13(1), 21-34.

Potvin, P., Mercier, J., Charland, P., \& Riopel, M. (2012). Does classroom explicitation of initial conceptions favour conceptual change or is it counter-productive? Research in science education, 42(3), 401-414.

Potvin, P., Sauriol, É., \& Riopel, M. (2015). Experimental evidence of the superiority of the prevalence model of conceptual change over the classical models and traditional teaching. Journal of Research in Science Teaching, 52(8), 1082-1108. doi:10.1002/tea.21235

Potvin, P., Turmel, É., \& Masson, S. (2014). Linking neuroscientific research on decision making to the educational context of novice students assigned to a multiple-choice scientific task involving common misconceptions about electrical circuits. Frontiers in human neuroscience, 8(14), 1-13. doi:10.3389/fnhum.2014.00014

Shtulman, A., \& Valcarcel, J. (2012). Scientific knowledge suppresses but does not supplant earlier intuitions. Cognition, 124, 209-215.

Solomon, J. (1983). Messy, contradictory, and obstinately persistent: A study of children's out-of-school ideas about energy. School Science Review, 65(231), 225-229.

Stavy, R., \& Babai, R. (2010). Overcoming intuitive interference in mathematics: Insights from behavioral, brain imaging and intervention studies. ZDM: The International Journal of Mathematics Education, 42(6), 621-633.

Stavy, R., \& Tirosh, D. (2000). How students (mis-)understand science and mathematics: Intuitive rules. New York and London: Teachers College Press.

Tyson, L., M., Venville, G., J., Harrison, A. G., \& Treagust, D. F. (1997). A multidimensional framework for interpreting conceptual change events in the classroom. Science Education, 81, 387-404. doi: 10.1002/(SICI)1098237X(199707)81:4<387::AID-SCE2>3.0.CO;2-8

Villani, A. (1992). Conceptual change in science and science education. Science Education, 76(2), 223-237.

Vlach, H. A., \& Sandhofer, C. M. (2012). Distributing learning over time: The spacing effect in children's acquisition and generalization of science concepts. Child Development, 83(4), 1137-1144. doi: 10.1111/j.1467-8624.2012.01781.x

Vosniadou, S. (1994). Capturing and modeling the process of conceptual change. Learning and Instruction, 4(1), 45-69.

Vosniadou, S. (2008). International handbook of research on conceptual change. New York, NY: Routledge. 